"C 2019 IEEE. Personal use of this material is permitted. Permission from IEEE must be obtained for all other uses, in any current or future media, including reprinting/republishing this material for advertising or promotional purposes, creating new collective works, for resale or redistribution to servers or lists, or reuse of any copyrighted component of this work in other works." 


\title{
Optimal Control of CHP Plant Integrated with Load Management on HVAC System in Microgrid
}

\author{
Haijie $\mathrm{Qi}^{1}$, Hong Yue ${ }^{1}$, Senior Member, IEEE, Jiangfeng Zhang ${ }^{2}$, and Steve $\mathrm{Lo}^{1}$
}

\begin{abstract}
Combined heat and power (CHP) is a typical community owned distributed generation solution in microgrid development. In this work, the ratio between the electricity output and the thermal output is controlled, along with the demand side load management, so as to minimize the overall microgrid operational cost. A model is established for the energy cost of a smart building system, which includes factors such as the real time electricity pricing, the capacity and constraints within CHP operation, the operating condition of heating, ventilation, and air - conditioning (HVAC), and the indoors air temperature of the smart building. Efficient CHP operation and HVAC load management under demand response (DR) are determined through optimization. A case study is carried out to examine the effectiveness of the proposed strategy.
\end{abstract}

Keywords - combined heat power (CHP); heating, ventilation, and air-conditioning (HVAC); microgrid; optimization; demand response $(D R)$

\section{INTRODUCTION}

Microgrids in power system provide an integration of distributed generations, especially from renewable energy sources. A typical microgrid operates as connected to the power grid but can also disconnect to "island model" depending on physical or economic conditions. The use of microgrids in power system reduces the distance between power plants and end-users, reduces the investment costs and improves the control stability and system protection in presence of faults. In view of environment concerns and the varying demands of end users (power demand, cooling and heating demand, etc.), future energy will be in the form of sustainable multi-energy systems [1], in which the smart energy hub (SEH) is the key unit. It includes energy flows and also the information flows between demand side and supplier side. Hence, the optimal control in SEH is considered critical to realize microgrid optimization.

The microgrids can be divided into three types: campus environment/institutional microgrids, community microgrids and remote off-grid microgrids [2]. All these microgrids can be managed by residential demand response (DR) analysis [3]. Instead of treating end-users as passive electricity consumers, DR enables the end-users to be manipulated according to the electricity price [4]. Rare work has been reported on the

${ }^{1}$ Haijie Qi, Hong Yue and Steve Lo are with the Department of Electronic and Electrical Engineering, University of Strathclyde, Glasgow, UK. (corresponding authors email: hong.yue@strath.ac.uk)

${ }^{2}$ Jiangfeng Zhang is with School of Electrical and Data Engineering, University of Technology Sydney, Sydney, Australia design of microgrids combining the optimal control of SEH and the DR on residential loads together. In conventional DR programs, the optimization is achieved by pre-acting or delaying some shiftable loads from peak electricity price region to valley electricity price region [5]. However, this single energy carrier DR is not suitable for end-users without shiftable loads. In addition, the frequent DR variations are inconvenient for consumers. Even when there are some shiftable applications in SEH, the end-users' DR capability cannot be fully exploited in conventional DR programs [6] . To achieve more capability of SEH, DR is combined to manage with electricity and gas energy conversion, which is called the integrated demand response (IDR). The IDR enables the integration of power grid, energy storage, and fossil fuel-based distributed generation.

In this work, the SEH includes a CHP system, in which the ratio of power and heat production can be controlled. It is used as the mean to achieve energy cost optimization. For buildings; such as those in hotels, hospitals, university campuses and office buildings, traditional boilers tend to be replaced by a higher efficiency heat equipment. A CHP system can get profit by saving fuel and selling the surplus electricity to the grid. A payback period of less than five years is achievable for systems of 15 years life period [7]. CHP system plays an important role in SEH, especially for switching energy suppliers and energy cost saving. A review of CHP's evaluation and development is presented in [8], including energy analysis, optimization and operation improvement. Constraints on CHP real-time control is discussed in [9]. In most existing CHP studies within microgrid, the CHP efficiency is considered separately from the demand side load management.

SEH makes it possible for customers to modify the energy flows from different sources and achieve demand side load management at the same time. The energy management system (EMS) is the brain of SEH functioned to analyze the DR signals and price information, then gives commands to each power and heat generation blocks on when to purchase electricity and gas to achieve profits. Recent studies on DR management with smart grid are reported for various systems. An optimal residential energy consumption schedule has been proposed considering multiple appliances and electricity storage system [10]. In[11], the optimal scheduling of typical home appliances to minimize electricity cost is discussed. A unit-commitment model is integrated with an economic model, where the unit-commitment model is used to calculate the performance of day-ahead electricity market and the economic model used to estimate the retailers' income and the price elasticities of electricity consumers under DR analysis 1 
[12]. For residential buildings, the major energy consumptions are used for space cooling and heating, which takes around $50 \%$ of the total energy consumption in developed countries [13]. In Europe the space heating is generally supplied by heating, ventilation, and air conditioning (HVAC) systems in smart commercial buildings [14]. It is therefore crucial to investigate control of CHP with consideration of load management on HVAC.

In this work, the CHP operation is controlled together with the microgrid load management so as to achieve the minimum total operational cost. The remaining of the paper is arranged as follows. In Section II, the energy cost model for a typical smart building is established including CHP and HVAC systems. The load management optimization is presented in Section III. A case study is conducted in Section IV to compare the proposed strategy with the conventional operation strategy. Conclusions are given in Section V.

\section{ENERGY COST MODELLING}

\section{A. Model Configuration}

As shown in Figure 1, the optimization model for the smart building in this work consists of (a) two energy sources: power grid and gas utility; (b) a distributed generation: CHP plant; and (c) the controlling center: EMS and two types of customer demands: electricity demand and thermal demand. Since the majority of electricity is consumed by HVAC system for space heating and cooling, the load management on HVAC is considered to be the main effort to realize DR in this work. The electricity demand is divided into HAVC load and other fixed loads, and the HVAC load management depends on the real-time electricity pricing, electricity sale tariff and the real-time customers' demands. In this model, EMS commands the behaviors of CHP plant, combined with the demand side management to operate the whole system with lower energy cost, instead of only considering the efficiency of CHP generation as in most previous studies.

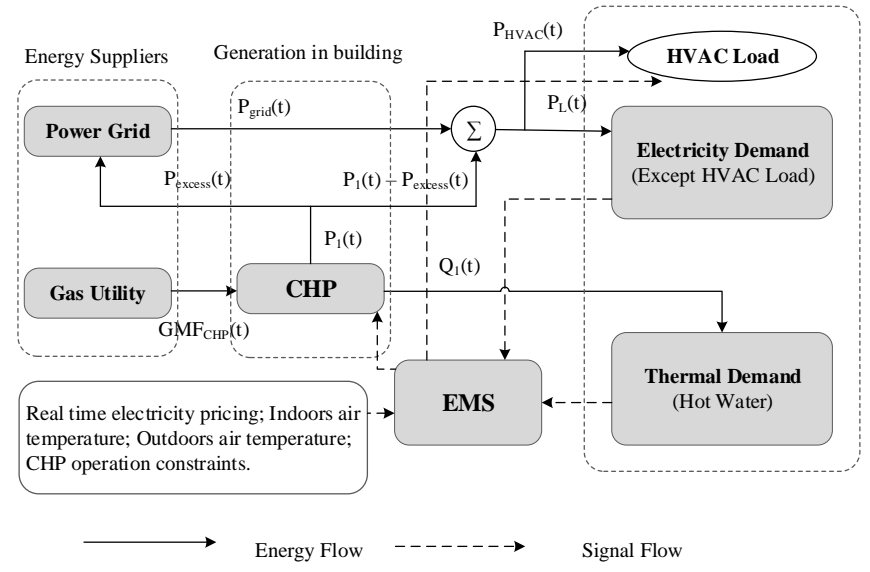

Figure 1. The proposed model of the smart building for optimization

The thermal demand is the hot water usage of the whole building, where the spacing heating is realized by the HVAC system. The amount of heat demand is relatively small. However, the highly efficient CHP operation accompanies with large amount of heat production. Thus, the CHP operation is decided by both the real-time electricity pricing and demand side adjustment. The other loads of electricity demand will be treated as firm loads, where the sum of these fixed loads is denoted as $P_{L}(t)$. At any time t, the electricity demand is supplied by the power grid, $P_{\text {grid }}(t)$, and the CHP power output, $P_{1}(t)$. GMF $F_{C H P}(t)$ is the gas mass flow used by CHP plant. The approach to dispose the excess electricity generated by CHP $P_{\text {excess }}(t)$ is to export it to the power grid. The management on HVAC load $P_{H V A C}(t)$ and CHP operation are both controlled by EMS to determine the optimal solution.

\section{B. Energy Cost Model}

The total energy cost of the smart building is considered from the perspective of the building's owner. The total energy bills include electricity bill and gas bill. Besides, the CHP can generate excess electricity at times, which can be sold to the power grid to get profit. Thus, the total energy cost $c_{\text {total }}$ for the smart building is written as follows.

$c_{\text {total }}=\sum_{t=1}^{T}\left(c_{1}(t) P_{\text {grid }}(t)+c_{2} G M F_{C H P}(t)-c_{3} P_{\text {excess }}(t)\right) \cdot \Delta t$

where $c_{1}(t)$ is the electricity price; $c_{2}$ and $c_{3}$ are the gas price and the electricity sale price, respectively, which are considered as constant in this model; $\Delta t$ is the sampling period for each time slot; $T$ is the total number of samples in time.

\section{1) Electricity payment}

The power purchased from power grid $P_{\text {grid }}(t)$ depends on the power output of CHP plant $P_{1}(t)$ and the power demand. The power demand in this model consists of the load management part $P_{H V A C}(t)$ and the fixed part $P_{L}(t)$, from other firm loads, thus:

$$
P_{\text {grid }}(t)=P_{H V A C}(t)+P_{L}(t)-P_{1}(t)+P_{\text {excess }}(t)
$$

In this model, $P_{1}(t)$ and $P_{H V A C}(t)$ are the controllable variables, the details are described in Section II.B.2) and section III respectively. The term $P_{\text {excess }}(t)$ is the excess power output of CHP plant, which only exists when the power output of CHP plant exceeds the power demand. If the power generation of CHP could not meet the end-users power demand at time $\mathrm{t}$, the $P_{\text {excess }}(t)$ will not exist and the customers need to buy electricity from grid.

$$
\begin{gathered}
P_{\text {excess }}(t)=\max \left\{P_{1}(t)-\left(P_{H V A C}(t)+P_{L}(t)\right), 0\right\} \\
P_{\text {excess }}(t) \cdot P_{\text {grid }}(t)=0
\end{gathered}
$$

\section{2) Gas payment}

The gas payment depends on the working condition of CHP plant. In this work, the CHP operation is handled as an hourly optimization problem. The decomposed CHP single-period model is formulated in convex case as linear 
programming problem. As shown in Figure 2, the production of heat and power of CHP plant is highly coupled. The power and heat can be produced at different ratios and costs, where the hourly control of CHP operation is necessary for the whole model optimization.

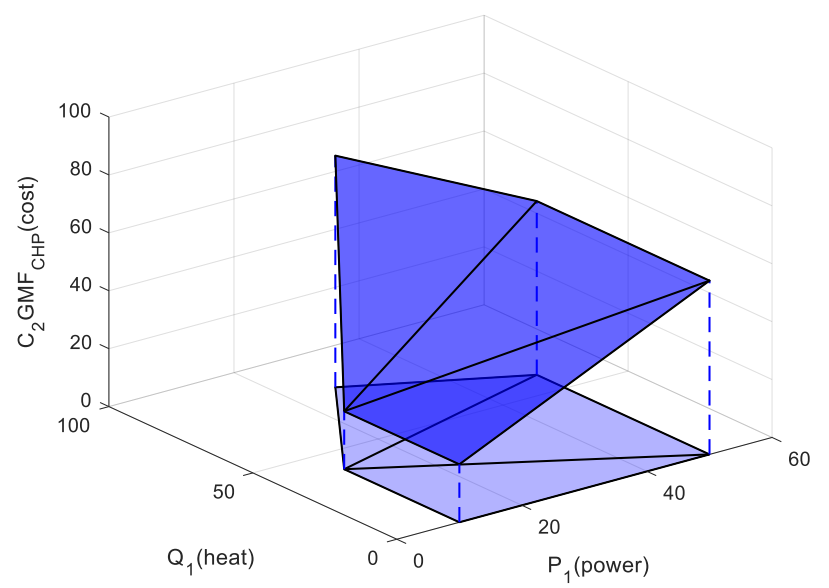

Figure 2. The convex operating region of CHP plant.

Each operating point in the region can be represented as a vector combinations of five characteristic points including $\left(u_{j}, p_{j}, q_{j}\right)$. Here $u_{j}$ is the value of CHP operation cost of characteristic point $j ; p_{j}$ and $q_{j}$ are the output power and heat of CHP plant, respectively. In a previous study [15], the hourly linear CHP optimization algorithm is established as represented in the following:

$$
\begin{gathered}
c_{2} G M F_{C H P}(t)=\sum_{j \in J} u_{j} x_{j}^{t} \\
P_{1}(t)=\sum_{j \in J} p_{j} x_{j}^{t} \\
Q_{1}(t)=\sum_{j \in J} q_{j} x_{j}^{t} \\
\sum_{j \in J} x_{j}^{t}=1 \\
0 \leq x_{j}^{t} \leq 1, \text { where } j \in J, t=1,2, \cdots N .
\end{gathered}
$$

where $Q_{1}(t)$ is the heat output of CHP generation at time slot $t$, which depends on the characteristic points of the CHP operation; $x_{j}^{t}$ is the decision variable, which encodes the vector combination of the operating region at time slot $t ; J$ is the set of number of characteristic points.

In this paper, five characteristic points are considered. Thus, $J=[1,2,3,4,5]$. It means there are five controllable variables $\left(x_{1}^{t}, x_{2}^{t}, x_{3}^{t}, x_{4}^{t}, x_{5}^{t}\right)$ in CHP optimal control. The gas payment can be modelled by characteristic points $\left(u_{j}, p_{j}, q_{j}\right)$ and the control variable $x_{j}^{t}$.
The power output of CHP must be smaller than the max power limit $P_{C H P}^{M A X}$. Besides, in order to protect the lifetime of CHP and improve the stability of whole system, the constraint on power ramping rate $p_{\text {ramp }}$ is applied, which restricts how much the power production of a CHP plant is allowed to increase or decrease between two successive time steps. Also, the hourly heat output $Q_{1}(t)$ must meet the hourly thermal demand $Q(t)$ considering the heat utilization efficiency $\eta^{\text {heat }}$. These give the following constraints.

$$
\begin{gathered}
P_{1}(t) \leq P_{C H P}^{M A X} \\
\left|\sum_{j \in J} p_{j} x_{j}^{t}-\sum_{j \in J} p_{j} x_{j}^{t-1}\right| \leq p_{\text {ramp }} \\
Q(t) \leq \eta^{\text {heat }} Q_{1}(t)
\end{gathered}
$$

In the above description, the time is discretized with 1 hour for each sampling period in the CHP modelling.

\section{INTEGRATED LOAD MANAGEMENT ON HVAC}

The HVAC system is normally the largest electricity usage appliance in a building, which requires load management for more economic use. The HVAC system has several operating power levels, $P_{l_{\text {HVAC }}^{H V A C}}$, each can be controlled as on/off status. Via regulating the on-off status of each working levels, the HVAC operating power $P_{H V A C}(t)$ can be controlled.

$$
\begin{gathered}
P_{H V A C}(t)=b_{l_{H V A C}^{H V A C}}(t) P_{l_{H V A C}^{H V A C}}^{H V \text { where }} l_{H V A C}=1,2, \cdots n \\
b_{l_{H V A C}}^{H V A C}(t) \in(0,1) \\
\\
\left\{\begin{array}{c}
\sum_{l_{H V A C} \in L_{H V A C}} b_{l_{H V A C}}^{H V A C}(t)=1, \text { on } \\
\sum_{l_{H V A C} \in L_{H V A C}} b_{l_{H V A C}}^{H V A C}(t)=0, o f f
\end{array}\right.
\end{gathered}
$$

where $b_{l_{\text {HVAC }}}^{\text {HVAC }}(t)$ is a binary variable indicating on/off status of HVAC at working level $l_{H V A C} ; n$ is the total number of HVAC working levels, which is considered to be five in case study of this work. Thus, at any time $t$, there are five operating levels $\left(l_{H V A C}=1,2,3,4,5 ;\right)$, and five corresponding binary variables in HVAC optimal control, i.e., $b_{1}^{H V A C}(t), b_{2}^{H V A C}(t), b_{3}^{H V A C}(t)$, $b_{4}^{H V A C}(t), b_{5}^{H V A C}(t)$.

Equation (15) shows that there is only one operating level of HVAC on at any time $\mathrm{t}$. In this model, the load management of HVAC aims to shape the system load so as to maximize the profit. The indoors air temperature $T_{t}^{i}$ needs to keep in an acceptable level. The indoors air temperature is affected by many factors, here the HVAC power transformation efficiency $\eta^{H V A C}$, the heat capacity of the building $C$, the outdoor ambient air temperature $T_{t}^{o}$, the ground temperature $T_{t}^{g}$, the ventilation temperature $T_{t}^{v}$ and their conductance 
with air temperature $\left(H^{i o}, H^{i g}, H^{i v}\right)$ are considered. $\eta^{\text {HVAC }} P_{\text {HVAC }}(t)$ is the HVAC effective power on the indoor air temperature. According to the indoors temperature balance function in ASHRAE Handbook, the power of HVAC system $P_{H V A C}(t)$ is formulated as below:

$$
P_{H V A C}(t)=\frac{C \frac{T_{t}^{i}-T_{t-1}^{i}}{\Delta t}-H^{i o}\left(T_{t}^{o}-T_{t}^{i}\right)-H^{i g}\left(T_{t}^{g}-T_{t}^{i}\right)-H^{i v}\left(T_{t}^{v}-T_{t}^{i}\right)}{\eta^{H V A C}}
$$

which can be used to calculate $T_{t}^{i}$ during the process. The following constraint is applied to indoors temperature:

$$
T_{\min }^{i} \leq T_{t}^{i} \leq T_{\max }^{i}
$$

$T_{\min }^{i}$ and $T_{\max }^{i}$ are the lowest and highest indoors temperatures. Here three parts of energy cost and profit are discussed in the proposed smart building energy cost model. All terms in (1) can be formulated by (2)- (3), (5)-(6), (13). Meanwhile, the constraints are established via (4), (8) - (12), (14) - (15), (17). Within any time slot $t$, there are 10 controllable variables denoted as $\phi$.

$$
\phi(t)=\left[x_{1}^{t}, x_{2}^{t}, \cdots, x_{5}^{t}, b_{1}^{H V A C}(t), b_{2}^{H V A C}(t), \cdots, b_{5}^{H V A C}(t)\right]
$$

Hence, the energy cost minimization problem for a typical smart building system can be established as follows in (19).

$$
\begin{aligned}
& c_{\text {total }}^{*}=\underset{\phi \in \Phi}{\arg \min } c_{\text {total }}(\phi) \\
& \text { s.t. } P_{\text {excess }}(t) \cdot P_{\text {grid }}(t)=0 \text {; } \\
& 0 \leq x_{j}^{t} \leq 1, j \in J ; \quad \sum_{j \in J} x_{j}^{t}=1 ; \\
& P_{1}(t) \leq P_{C H P}^{M A X} \text {; } \\
& \left|P_{1}(t)-P_{1}(t-1)\right| \leq p_{\text {ramp }} ; \\
& \eta^{\text {heat }} P_{1}(t) \geq Q(t) \text {; } \\
& b_{l_{\text {HVAC }}}^{H V A C}(t) \in(0,1) \text {; } \\
& \left\{\begin{array}{l}
\sum_{l_{\text {HVAC }} \in L_{H V A C}} b_{l_{\text {HVAC }}^{H V A C}}(t)=1 \text {, on } \\
\sum_{l_{\text {HVAC }} \in L_{H V A C}} b_{l_{\text {HVAC }}^{H V A C}}(t)=0, \text { off }
\end{array}\right. \\
& T_{\min }^{i} \leq T_{t}^{i} \leq T_{\max }^{i}
\end{aligned}
$$

This is a mixed-integer programming problem, and it is a complex global optimization problem. An advanced global method, Genetic Algorithm (GA), will be selected to solve this problem. GA simulates the biological processes of reproduction and natural selection to find the optimal solution, which has good convergence, low computation time and high robustness under precision requirement [16].

\section{CASE STUDY}

This case study aims to verify the optimization effect of the IDR model with CHP optimal control and load management on HVAC. The research data is taken from survey data of a large hotel in Miami, USA. The model is simulated with real-time electricity price and indoors air temperature, as shown in Figure 3. The setting of constant parameters are listed in Table 1. The aim of optimal control of CHP and load management on HVAC system is to minimize the total building's energy cost, while meeting with the requirements of power and heat demands, and keep the indoors air temperature within a comfortable range.

Table 1. Setting of parameters

\begin{tabular}{|l|l|l|l|}
\hline Para. & Values & Para. & Values \\
\hline$c_{3}(£)$ & $0.05 / k W \cdot h$ & $H^{i o}$ & $0.055 \mathrm{~kW} /{ }^{\circ} \mathrm{C}$ \\
\hline$u_{j}(£)$ & $(8,8,48,36,35)$ & $H^{i v}$ & $0.019 \mathrm{~kW} /{ }^{\circ} \mathrm{C}$ \\
\hline$p_{j}(k W)$ & $(100,100,250,500,500)$ & $H^{i g}$ & $0.09 \mathrm{~kW} /{ }^{\circ} \mathrm{C}$ \\
\hline$q_{j}(k W)$ & $(10,100,400,240,10)$ & $\eta^{H V A C}$ & 0.85 \\
\hline$P_{C H P}^{M A X}$ & $500 \mathrm{~kW}$ & $C$ & $3071 \mathrm{~J} /{ }^{\circ} \mathrm{C}$ \\
\hline$P_{\text {ramp }}$ & $100 \mathrm{~kW}$ & $T_{t=0}^{i}$ & $16^{\circ} \mathrm{C}$ \\
\hline$P_{1}(t=0)$ & 0 & $T_{\min }^{i}$ & $16^{\circ} \mathrm{C}$ \\
\hline$\eta^{\text {heat }}$ & 0.85 & $T_{\max }^{i}$ & $24^{\circ} \mathrm{C}$ \\
\hline
\end{tabular}

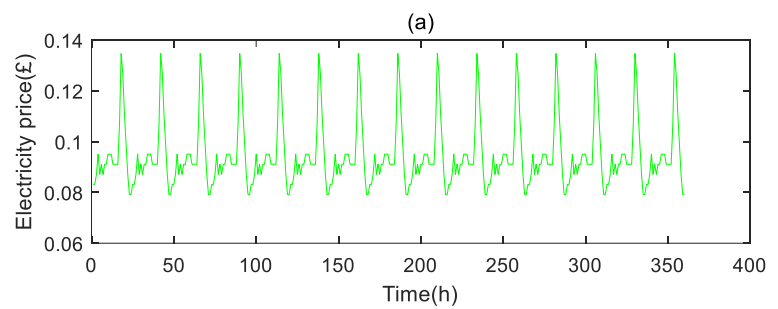

(b)

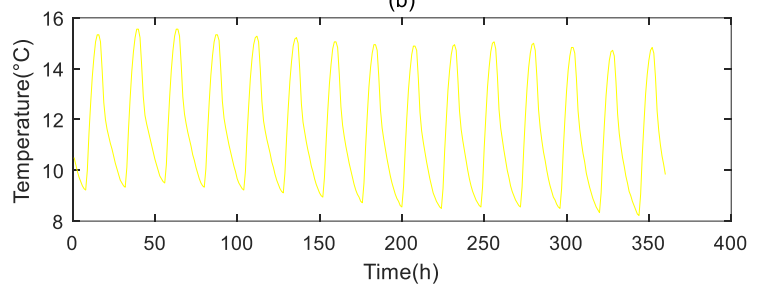

Figure 3. Real-time electricity price and outside air temperature.

In this simulation, the time range is set to be 360 hours, and each sampled time slot is 1 hour. In several figures showing simulation results, the time range is set to 120 hours in order to better illustrate the power curve of HVAC.

In the initial operating scenario, there is no load management applied on HVAC, which means $P_{H V A C}(t)$ and $P_{L}(t)$ are not controlled. All the electricity demands are supplied by power grid, and the thermal demand of the hotel is supplied by gas boiler. There's no CHP generation in the initial model. It is assumed that there is no loss of electricity transmission from power grid to appliances. The energy usage and the cost from the initial model without HVAC optimization are shown in Figure 4, from which it can be seen that the building's electricity power demand is much higher than the thermal demand since the space heating is realized by HVAC system. The total energy bill is the sum of the electricity bill and the gas bill, which is mainly from the higher part of the electricity bills. 


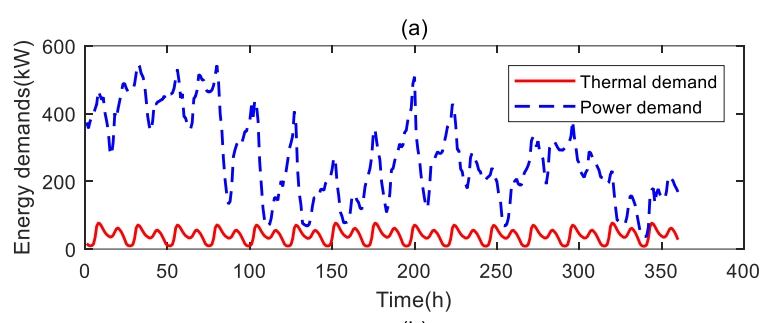

(b)

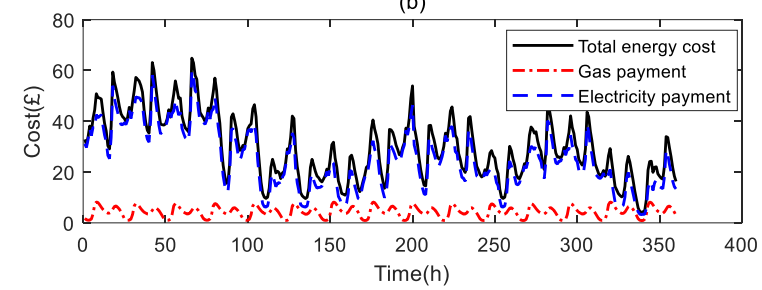

Figure 4. Energy usage and cost for initial model without optimization.

The load variation of the HVAC system from the initial setting and from the optimized calculation are shown in Figure 5, where it can be observed that the load of HVAC is reduced significantly through the optimization. The temperature profile is shown in Fig.6, where the indoor temperature is controlled between the range of $16^{\circ} \mathrm{C}$ and $24^{\circ} \mathrm{C}$.

In this case study, the power of HVAC is also affected by other factors to make the whole smart building operate with lowest energy cost during a time period, e.g. the outdoors temperature and the real-time electricity price. From the viewpoint of cost optimization over a longer period of time rather than a single time slot, the HVAC system can actually work at a higher power level to keep the building temperature when the electricity price is low, which will allow operation at a lower level when the electricity price is high.

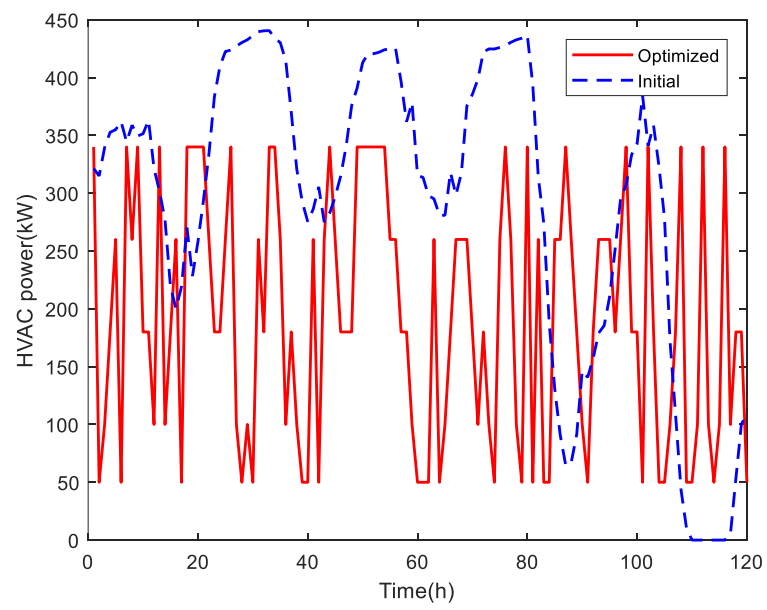

Figure 5. The HAVC loads variation in initial and optimized operation.

The indoors air temperature is affected by the power of HVAC and the outside air temperature, which is expressed in (16). In Figure 6, the curve of $P_{H V A C}(t)$ normally decreases when the electricity price rises, but it is not always the case. This is because the power grid is not the only electricity supplier, CHP can also provide electricity to the smart building. As shown in Figure 7 , the CHP $\left(P_{1}\right)$ operates at a higher level because of its lower cost ratio for energy production in comparison with the power grid. As shown by the constraint in (4), the $P_{\text {excess }}(t)$ and the $P_{\text {grid }}(t)$ do not appear at the same time. Although the CHP has a competitive cost performance, it doesn't work at its highest power output level, which is $500 \mathrm{~kW}$ for this system. This is because the thermal demand is relatively low (see Fig.4a).

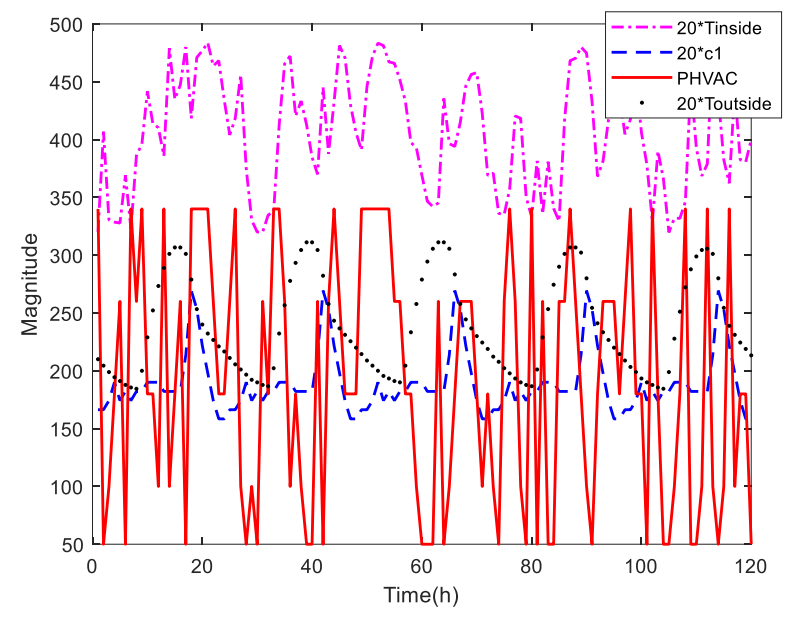

Figure 6. Optimized HVAC loads, temperatures and electricity price.

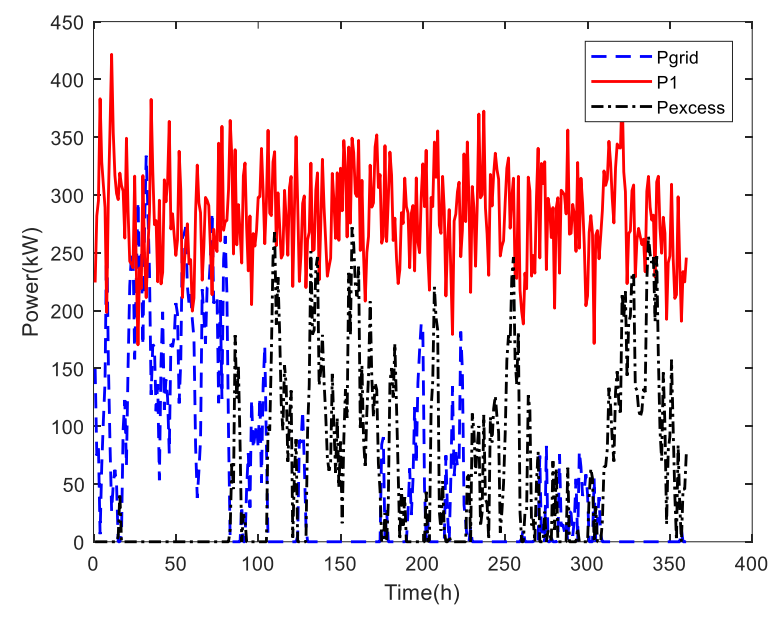

Figure 7. Power bought from grid and generated by CHP plant.

The energy cost within a single time slot is expressed as

$C_{\text {Temp }}(t)=\Delta t \cdot\left(c_{1}(t) P_{\text {grid }}(t)+c_{2} G M F_{C H P}(t)-c_{3} P_{\text {excess }}(t)\right)$

Comparing $C_{\text {Temp }}(t)$ with the electricity payment in Figure 8 , the larger amount of electricity bought from power grid leads to the peak value of energy bills. Much electricity bought from power grid leads to more expensive bills at early testing time. Hence, it should be noticed that $P_{\text {grid }}(t)$ is the significant factor to high energy bills. CHP helps the system to save money by relatively lower generation cost and exporting the excess electricity to the grid. 


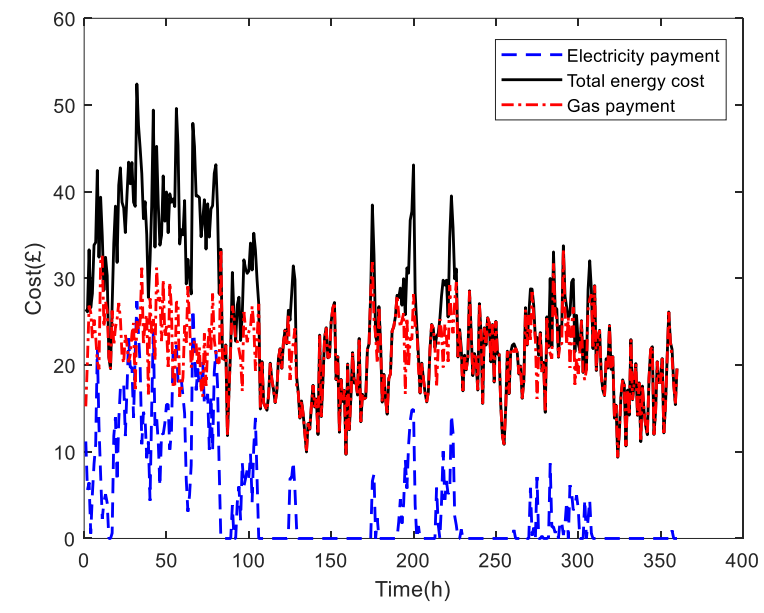

Figure 8 . Energy bills in newly proposed optimization model.

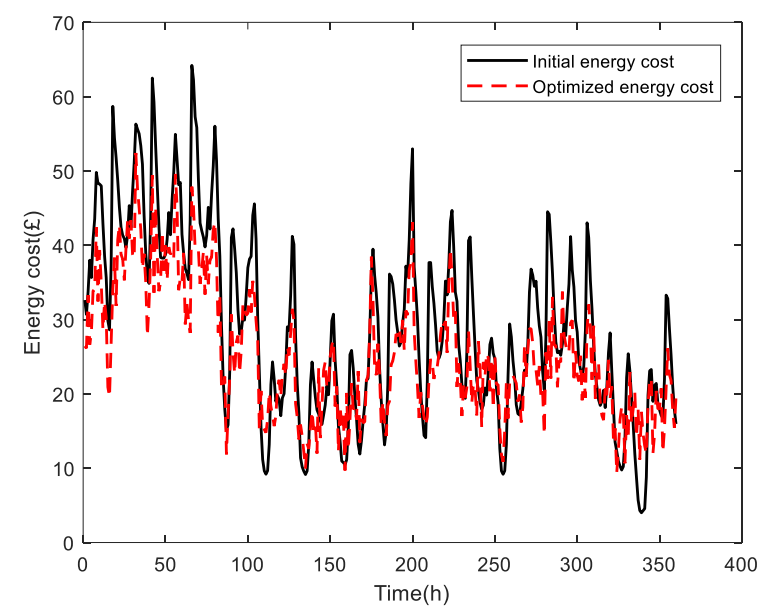

Figure 9. Total energy cost comparison.

According to Figure 9, the optimized energy cost curve is relatively smoother, with smaller peak values, compared with the case without optimization. The load management in this work only focuses on the HVAC system, the remaining fixed loads are not controlled, thus, the main tendency of the energy usage curve doesn't change much. As a result, the total energy cost of the smart building operating in the simulation is around 9,350 pounds, where the original energy bills in 15 days is 10,701 pounds. The model with both load management on HVAC and CHP optimal control has saved $12.6 \%$ of energy cost in this case study.

\section{CONCLUSIONS}

An energy cost model is established and utilized to realize the CHP optimal control integrated with the load management on HVAC. The development in this work suggests the possibility to combine the optimal operation of microgrid with DR program. Through the case study, it is revealed that a clear reduction of total energy cost can be achieved with the use of the proposed optimization strategy. Further investigation will be focused on testing the two partial-optimization models, which consider CHP hourly optimal control and load management on HVAC, separately. It will aim to test the interaction effect between the CHP optimal control and the load management on HVAC. The energy storage systems, photovoltaic systems, electrical vehicles, will also be considered to expand the scale of smart-building model to include wider applications.

\section{REFERENCES}

[1] M. Mohammadi, Y. Noorollahi, B. Mohammadi-ivatloo, M Hosseinzadeh, H. Yousefi, and S. T. Khorasani, "Optimal management of energy hubs and smart energy hubs - A review," Renewable and Sustainable Energy Reviews, vol. 89, pp. 33-50, 2018.

[2] M. Saleh, Y. Esa, Y. Mhandi, W. Brandauer, and A. Mohamed, "Design and implementation of CCNY DC microgrid testbed," in 2016 IEEE Industry Applications Society Annual Meeting, 2-6 Oct. 2016 2016, pp. 1-7.

[3] K. H. S. V. S. Nunna and S. Doolla, "Responsive End-User-Based Demand Side Management in Multimicrogrid Environment," IEEE Transactions on Industrial Informatics, vol. 10, no. 2, pp. 1262-1272.

[4] O. Kilkki, A. Alah, x00E, iv, and I. Seilonen, "Optimized Control of Price-Based Demand Response With Electric Storage Space Heating," IEEE Transactions on Industrial Informatics, vol. 11, no. 1, pp. 281-288, 2015

[5] P. Palensky and D. Dietrich, "Demand Side Management: Demand Response, Intelligent Energy Systems, and Smart Loads," IEEE Transactions on Industrial Informatics, vol. 7, no. 3, pp. 381-388, 2011.

[6] J. Wang, H. Zhong, Z. Ma, Q. Xia, and C. Kang, Review and Prospect of Integrated Demand Response in the Multi-Energy System. 2017.

[7] M. Ebrahimi and A. Keshavarz, "1 - CCHP Literature," in Combined Cooling, Heating and Power. Boston: Elsevier, 2015, pp. 1-34.

[8] H. Cho, A. D. Smith, and P. Mago, "Combined cooling, heating and power: A review of performance improvement and optimization," Applied Energy, vol. 136, pp. 168-185, 12/31/ 2014.

[9] H. Wang, W. Yin, E. Abdollahi, R. Lahdelma, and W. Jiao, "Modelling and optimization of CHP based district heating system with renewable energy production and energy storage," Applied Energy, vol. 159, pp. 401-421, 12/1/ 2015.

[10] D. Setlhaolo and X. Xia, "Optimal scheduling of household appliances with a battery storage system and coordination," Energy and Buildings, vol. 94, pp. 61-70, 5/1/ 2015.

[11] D. Setlhaolo, X. Xia, and J. Zhang, "Optimal scheduling of household appliances for demand response," Electric Power Systems Research, vol. 116, pp. 24-28, 2014/11/01/ 2014.

[12] A. S. Dagoumas and M. L. Polemis, "An integrated model for assessing electricity retailer's profitability with demand response," Applied Energy, vol. 198, no. Supplement C, pp. 49-64, 2017/07/15/ 2017.

[13] L. Pérez-Lombard, J. Ortiz, and C. Pout, "A review on buildings energy consumption information," Energy and Buildings, vol. 40, no. 3, pp. 394-398, 2008/01/01/ 2008.

[14] I. Beil, I. Hiskens, and S. Backhaus, "Frequency Regulation From Commercial Building HVAC Demand Response," Proceedings of the IEEE, vol. 104, no. 4, pp. 745-757, 2016.

[15] A. Rong, H. Hakonen, and R. Lahdelma, "An efficient linear model and optimisation algorithm for multi-site combined heat and power production," European Journal of Operational Research, vol. 168, no. 2, pp. 612-632, 2006/01/16/ 2006.

[16] D. E. Goldberg and J. H. Holland, "Genetic Algorithms and Machine Learning," Machine Learning, vol. 3, no. 2, pp. 95-99, 1988. 